Revista Iberoamericana, Vol. LXXII, Núms. 215-216, Abril-Septiembre 2006, 531-544

\title{
EL TESTIMONIO COMO ELABORACIÓN DEL TRAUMA EN 'MALUCO: LA NOVELA DE LOS DESCUBRIDORES’ DE NAPOLEÓN BACCINO
}

\author{
POR \\ Paula Chiara \\ University of Minnesota
}

La conquista de América y el encuentro entre españoles e indígenas es un tópico recurrente en la narrativa latinoamericana actual. En su artículo "Trauma, Absence and Loss”, Dominique LaCapra se refiere a la necesidad que enfrentan sociedades como la sudafricana pos-apartheid o la alemana pos-nazi de elaborar las pérdidas y la violencia de su pasado. Podemos decir lo mismo de los pueblos latinoamericanos que una y otra vez se ven enfrentados a un pasado de violencia producto de la conquista. En el contexto latinoamericano encontramos un ejemplo del proceso explicado por LaCapra según el cual el trauma histórico se convierte en un trauma fundante, mito del origen, base para la identidad colectiva (LaCapra 724). El problema de la identidad en Latinoamérica esta íntimamente relacionado con el sitio del trauma histórico, el encuentro violento entre dos civilizaciones que se desconocen ¿Qué significa para la historia ser la historia de un trauma? ¿Qué significa para la identidad latinoamericana ser producto del encuentro violento entre el español y el indígena? Es posible visualizar la estructura recurrente, repetitiva del trauma en la producción cultural latinoamericana, en donde el tópico de la conquista y la problemática de la identidad vuelven incesantemente: "The trauma of that historical encounter, genocide, violation, and "hybridization" haunt even the most parodic narratives as well as the most linear" (Bishop 160). Desde esta perspectiva podemos entender las novelas metahistóricas latinoamericanas como un intento de elaboración y resignificación de un pasado conflictivo.

En este trabajo me interesa detenerme en el análisis de la construcción de la memoria en Maluco. La novela de los descubridores de Napoleón Baccino, prestando especial atención a la manera en que se representa el trauma histórico vivido por los personajes. Me interesa analizar la relación entre el sufrimiento vivido por Juanillo, bufón de la flota y narrador de la historia, y su representación discursiva. Con este fin utilizo la noción de trauma histórico, ${ }^{1}$ propuesta por LaCapra y algunos aportes de Trauma Theory, ${ }^{2}$ entre ellos su noción de una temporalidad no lineal. Como sostiene Cathy Caruth, una de las figuras

\footnotetext{
${ }^{1}$ Dominick LaCapra hace una distinción entre trauma histórico y trauma estructural. Mientras el trauma estructural está presente en todas las sociedades y en la vida de todos los hombres el trauma histórico es específico y está relacionado a eventos históricos específicos: "Structural trauma may be evoked or addressed in various fashions-in terms of the separation from the mother, the passage from nature to culture, the eruption of the pre-oedipal or pre-symbolic in the symbolic, the entry into
} 
más destacadas dentro de los estudios de Trauma Theory: "Trauma Theory reworks deconstruction in line with a notion of history or temporality that is profoundly psychoanalytical, and which is based in notions of repetition, return, and belatedness" (Caruth, “Trauma, Silence, and Survival” 5).

Para analizar la respuesta narrativa de Juanillo a estos hechos potencialmente traumáticos utilizo el concepto psicoanalítico de Working Through o Trabajo de elaboración. ${ }^{3}$ El concepto de Trabajo de elaboración nos permite entender el procesamiento individual o colectivo de la experiencia traumática. La narración verbal en los adultos así como el juego o narración lúdica en los niños son formas privilegiadas de elaborar dichas experiencias. Freud utiliza el término “trabajo” porque según su hipótesis el aparato psíquico se ve en la necesidad de transformar la cantidad de energía que lo inunda (trauma), para poder controlarla por medio de la abreacción (expresión del afecto) y la ligazón o realización de conexiones asociativas. Cuando el trabajo de elaboración tiene lugar el sujeto logra liberarse de la compulsión a la repetición propia del trauma. Por el contrario cuando el trabajo de elaboración, y la simbolización que este implica, se ven obstaculizados prima la repetición y el retorno de lo reprimido. Como sostienen van der Kolk y van der Hart si la experiencia no puede ser organizada a nivel lingüístico "this failure to arrange the memory in words and symbols leaves it to be organized on a somatosensory or iconic level: as somatic sensations, behavioral reenactments, nightmares and flashbacks" (Van der Kolk 172). En este ensayo propongo que el testimonio de Juanillo sirve como trabajo de elaboración del trauma.

Hasta el momento la crítica sobre Maluco se ha detenido en el carácter paródico de la novela, a través de la cual se cuestiona el discurso histórico oficial; en su apropiación de formas discursivas propias del siglo xvi como crónicas y relación de servicios; en la herencia renacentista de la tradición picaresca o bufonesca y en la intertextualidad y el

language, the encounter with the real, alienation from species-being, the constitutive nature of originary melancholic loss in relation to subjectivity, and so forth”. El trauma estructural está relacionado con el concepto de ausencia mientras que el trauma histórico se relaciona al concepto de pérdida: "Absence appears in all societies or cultures" (701) "By contrast to absence loss is situated in a historical level and is the consequence of particular events" (712). Me interesa esta noción de trauma histórico porque nos permite localizar en el tiempo el evento traumatizante y conservar la distinción entre el evento y la respuesta del sujeto frente al evento. En los estudios de Trauma Theory muchas veces se alude al término trauma no para referirse al momento original de la experiencia sino a la acción diferida de carácter repetitivo que tiene lugar en la vida del sujeto. ${ }^{2}$ En los últimos años, como consecuencia de las innumerables guerras vividas a lo largo del siglo, ha crecido considerablemente el interés por el estudio de experiencias traumáticas y sus efectos en la vida de los individuos. En las teorizaciones recientes sobre trauma se sigue en general los trabajos pioneros de Freud, que dan centralidad al concepto de repetición y temporalidad diferida del trauma. Dos figuras centrales de lo que se llama Trauma Theory son Cathy Caruth y Shoshana Felman a quienes nos referimos en el presente trabajo.

${ }^{3}$ Según Laplanche y Pontalis "working through might be defined as that process which is liable to halt the repetitive insistence characteristic of unconscious formations by bringing these into relation with the subject's personality as a whole” (The Language of Psychoanalysis 489). 
carácter polifónico presentes en la novela. ${ }^{4}$ Los críticos han enfatizado la fuerza paródica, la risa, la burla y la ironía como estrategias utilizadas para crear una visión alternativa al discurso oficial sobre el viaje de Magallanes, pero no se han detenido considerablemente en la representación discursiva del trauma ni en la fuerte carga humana, de sufrimiento presente en la novela.

La novela es desde esta perspectiva uno de los múltiples intentos novelísticos de recuperar y recrear desde el presente un pasado de violencia y dolor. Pienso que esta perspectiva de análisis nos permite entender la novela dentro del contexto histórico de su producción. Un contexto de represión, de violencia, de silencios. En la narración de Juanillo se enfatiza la importancia de sacar a luz el sufrimiento humano y los horrores del viaje ocultados por los cronistas oficiales. El silencio y la represión atraviesan el viaje, la imposibilidad de expresión se simboliza en el castigo infligido a dos de los tripulantes: a Andrés el cartógrafo se le corta la lengua y con ella toda posibilidad de habla, a Cartagena se le cortan las manos y con ellas toda posibilidad de dar a conocer por escrito lo ocurrido. El lector es capaz de vincular estos símbolos textuales con el contexto histórico de producción de la novela, en donde priman la violencia y la imposibilidad de libre expresión. Baccino escribe su novela durante el período de la dictadura militar uruguaya que va desde 1973-1985. Son años marcados por la violencia, la represión, el silencio forzado y un intento por parte de los militares de apoderarse del discurso histórico nacional y re-escribirlo. Desde esta perspectiva se puede entender la novela de Baccino como trabajo de elaboración de la experiencia vivida, como respuesta creativa frente a la misma. El propio Baccino sugiere dicha interpretación cuando en una entrevista con Juanamaría Cordones-Crook sostiene:

\footnotetext{
${ }^{4}$ Según Mignolo el término Crónicas se refiere a una tradición discursiva que narra los descubrimientos y conquistas de los siglos XVI y xvII. Designa un grupo de textos producidos en el período colonial de Latinoamérica que incluye diversos subtipos: cartas de relación, diario de viaje, historias (Hernández 4). El término Relación de Servicio se refería en el siglo XVI a un documento legal en el cual el emisor contaba su historia y los hechos pertinentes a su caso, basado en su autoridad como testigo (Hernández 4). En su ensayo "Maluco: reescritura de los relatos de la expedición de Magallanes" Malva Filer hace referencia a los elementos de la tradición picaresca presentes en la novela. En primer lugar Juanillo invoca la "necesidad" y el "hambre" como razones para escribir su petición a Carlos V, se refiere a si mismo como "truhán”, término renacentista para referirse al pícaro. Siguiendo la tradición picaresca del Lazarillo, Juanillo sirve varios amos y alude a su origen ilegítimo, hijo de una prostituta y un converso. En la misma línea Florencia Garramuño considera el prólogo de Maluco como una reescritura hiperbólica del prólogo de Lazarillo dirigido a "Su Alteza”. Para Hernández en cambio el personaje Juanillo pertenece a la tradición literaria del bufón del siglo de oro español y no a la tradición picaresca. Para Hernández, Malva Filer no toma en cuenta la sofisticación literaria y cultural de este pícaro. Juanillo demuestra un conocimiento sólido de la historia y literatura clásica y medieval así como un gran lirismo en su uso del lenguaje. Juanillo incorpora en su narración historias intercaladas y anécdotas al estilo cervantino e insulta o denuncia a Carlos V como lo hace Lope de Aguirre con Felipe II en su carta de 1556. Sostiene Hernández "None of these elements are common in picaresque literature and points the reader to the Spanish buffonesque literary tradition. Juanillo is a bufón (not a pícaro) who enacts the role of the pícaro and the chronicler” (Hernández 5). Personalmente no veo que ambas posturas sean excluyentes, lo que está claro es que Baccino se apropia de ambas tradiciones españolas para escribir su novela.
} 
Esta novela nació como todas en la circunstancia vital que la explica en parte, en una dictadura que había prohibido las palabras. Yo sentí que la mejor respuesta para la mordaza de esos años, que sufrí como todos mucho, era narrar desde el punto de vista de un bufón que gozaba hasta el privilegio de decir lo que se le antojara. (106)

No es menor la fuerza connotativa del término "mordaza" para comprender la significación de la novela como respuesta creativa. El personaje del Bufón y la ubicación temporal de la peripecia novelística, tan alejada de la realidad uruguaya, le brindan a Baccino la libertad de decir en su ficción todo aquello que debe callar respecto a su presente histórico. Juanillo habla del miedo, de la incertidumbre, de la separación de los seres queridos, de la violencia, del silencio, de ese “calabozo de la angustia”. A través del testimonio de Juanillo, Baccino le sugiere al lector la posibilidad futura de recuperar una historia de dolor y violencia que se vive en el contexto uruguayo pero que como en el relato de Pigafetta se intenta callar y enmendar. Siempre habrá testigos de la historia, Baccino parece sugerir que al silencio y al olvido siempre sigue la recuperación de la memoria a través de la palabra. El testimonio aparece como una vía posible de develar los secretos de la historia oficial.

En este sentido pienso que la reflexión en cuanto al papel del escritor y su relación con la historia subyace la novela. ¿Cuál es la función del escritor como testigo de la historia? o como se pregunta Shoshana Felman; "How is the act of writing tied up with the act of bearing witness? Is the act of reading literary texts itself inherently related to the act of facing horror?” (Caruth, Trauma 14). Cuando el discurso histórico está plagado de silencios es a través del arte que se recupera la voz y la posibilidad de representar y simbolizar lo incomprensible e intransferible del sufrimiento humano. Es por ello que para Theodor Adorno el arte es "the only remaining medium of truth in an age of incomprehensible terror and suffering” (Schweizer 3), el arte es un espacio de construcción y reconstrucción de la memoria colectiva a partir de un incesante proceso de simbolización y resignificación del pasado. En su libro Suffering and The Remedy of Art Harold Schweizer se refiere a la relación entre el sufrimiento humano y su representación artística: "even if artistic representation is fundamentally attuned to the incommesurability of its cause, all art must lastly compromise the incomprehensible by transforming the formless into the form and the unsharable truth of suffering into bearable fictions” (3).

Pienso que en Maluco Napoleón Baccino nos transmite su confianza en este poder liberador del lenguaje, de la imaginación, del juego, en definitiva del arte, oponiendo al miedo y al silencio la reconquista de la palabra que permite a las víctimas compartir su dolor y recuperar posteriormente sus historias, como modo de elaborar lo ocurrido y restaurar sus identidades fragmentadas. Un ejemplo claro, especie de catársis colectiva, lo encontramos en el capítulo VII donde los tripulantes a través del juego de palabras e imágenes intentan dar forma a sus sentimientos, a aquello que de otra forma les resulta incomprensible: la soledad, la muerte, la vida, el paso del tiempo:

¿Qué es la soledad para ti?

-Una casa cerrada.

-Una cuna vacía. 
-Eso es la muerte -digo.

-Y también la soledad. Son la misma cosa.

-La soledad es una planta que te crece en el pecho y echa raíces tan fuertes que no puedes quitártela.

Problematización DE LA ESCRITURA HISTÓRICA

Maluco forma parte de lo que se conoce como la nueva novela histórica latinoamericana, en la cual se rescribe la historia oficial a la vez que se problematiza la función de la escritura y la escritura de la historia. ${ }^{5}$ En Maluco se problematiza la escritura de la historia de varias maneras: a través de la parodia y la ironía, a través del carácter autobiográfico del testimonio que introduciendo una mirada subjetiva e interpretativa de los acontecimientos desafía la objetividad del discurso histórico, a través de la puesta en evidencia de la artificialidad de la escritura misma.

La historiografía según Michel de Certeau "denotes the practice of constructing meaning about the past in written form" "it seeks to produce the real in discursive form" (Fiddian 144-145). Pero podemos preguntarnos aquí por el significado de "lo real” ¿qué es lo real para la historia? Baccino cuestiona en esta novela la concepción positivista que durante mucho tiempo ha tenido la historia acerca de lo “real”. ¿No son también, como sostiene García Márquez, parte de la realidad los mitos de la gente, sus fantasías, sus miedos, todo aquello que forma parte de la vida humana? Juanillo alude en su testimonio al proceso de deshumanización que produce la escritura histórica tornando en nombres y cifras la gran variedad de hombres que componían la tripulación; padres, hijos, esposos, solitarios; marineros, capitanes, contramaestres, toneleros, lombarderos, criados; grandes y pequeños; ricos y pobres:

Pero para Vuestra Alteza, nada, una lista más de nombres cuya sola lectura no soportarías por aburrida ya que no puedes imaginarte ni uno. Nombres en una lista y números en un papel. Todos sin rostros, sin manos, sin pies, sin miembro, sin ojos, sin boca, sin oreja, sin culo, sin olor. (Baccino 52)

Al respecto considero que uno de los aspectos más logrados en la novela de Baccino es justamente la rehumanización de ciertas figuras históricas como el Rey Carlos V y

\footnotetext{
${ }^{5}$ Para un estudio de la nueva novela histórica latinoamericana sobre la conquista y colonización de América ver Kimberle López. Latin American Novels of the Conquest: Reinventing the New World. Dentro de esta categoría señala un corpus de novelas que narran la experiencia de la conquista y colonización desde la perspectiva de un personaje ficticio marginal, generalmente hombre y europeo. Algunas de las novelas mencionadas de la última década son: La huella del conejo (Julián Meza, 1991), Crónica de las Destrucciones ( Olivier Debroise, 1998), Yo me perdono (Fietta Jarque, 1998), En busca del paraíso (Juan Cárdenas Miño, 1998), Amor y Conquista (Marison Martín del Campo, 1999) Esta maldita lujuria (Elio Brailovsky, 1991) Terra Papagalli (Roberto Torero y Marcus Aurelius Pimenta, 1997), El conista perdido (Hugo Muller, 1998) Invasores del Paraíso (Heminio Martínez, 1998), El regreso (Heminio Martínez,1999). Todas estas novelas, al igual que Maluco de Napoleón Baccino Ponce de León, deconstruyen la retórica de la conquista a través de la introducción de una perspectiva marginal de los acontecimientos.
} 
Magallanes. Baccino da a este último personaje una gran profundidad humana a través de los diálogos con Juanillo, diálogos en donde se construye una relación entre los personajes que recuerda al lector la relación Sancho-Don Quijote. En cuanto a la humanización de Carlos V, Amalia Iniesta Cámara menciona varios procedimientos utilizados por el narrador cronista con dicho fin: su tono coloquial, el uso de interrogaciones directas e indirectas, los imperativos irónicos, el uso de anafóricos al dirigirse al rey "El narrador cronista-bufón recupera la situación dialógica con el Rey Carlos V, aun en ausencia de la respuesta de aquél, pues la imagina, la contempla” (Iniesta Cámara 64).

Otro elemento central del cuestionamiento al discurso histórico propuesto por Baccino es la relación entre historia y poder. Para Baccino no existe una historia sino tantas historias como historiadores. La representación histórica como construcción narrativa de la realidad depende del lugar de enunciación y su posición con respecto al poder. Baccino alude al carácter conflictivo del termino "real” y sugiere esta relación entre poder y conocimiento a través de un juego de palabras. Juanillo al dirigirse a Carlos V se refiere a los tripulantes de las cinco naves del siguiente modo “doscientos y tantos hombres como vos, no tan Reales no menos reales. Con sed, con hambre, con sueño, con ilusiones, con miedo" (Baccino 52). Baccino juega con la doble significación del término "real” para sugerir como sostiene Perkowska "that in traditional historiography only those who are "royal”... are also "real” because they enter history through writing. For being real only with a lower-case " $r$ " the subaltern classes are situated outside the space where history is made” (Perkowska 254). En el testimonio de Juanillo escrito desde una posición crítica existe una demanda de ser escuchado, un esfuerzo por ganar un lugar en la historia que le ha sido negado: "si ni siquiera figura mi nombre en las crónicas y se me ha borrado de las listas de sobrevivientes de aquella expedición al Maluco por la que tanto hice...” (Baccino 306). Juanillo intenta acceder a la escritura como herramienta de poder con varios fines: escribe en primer lugar para exigir un derecho que le pertenece, el derecho a su pensión; escribe para ganar su lugar en la historia y desenmascarar las mentiras de la historia oficial; pero escribe también como un modo de elaborar el trauma de lo vivido y restaurar una memoria e identidad fragmentada: "the transformation of the trauma into narrative memory allows the story to be verbalized and communicated, to be integrated into one's own and other's past” (Caruth, Trauma 153).

Como nos lo muestra Juanillo en su testimonio, es a través del lenguaje que se recupera el pasado y se le da un nuevo sentido. El discurso histórico recupera el pasado desde un presente creando una distancia entre el evento histórico y su representación, pero mientras el testimonio reconoce esta distancia como naturalmente conflictiva, la historia como sostiene de Certeau muchas veces la intenta ocultar: "Historiography pretends to represent past realities and in pursuing that aim, does all it can to conceal the meaning of its own operation” (Fiddian 146). En el discurso histórico en tercera persona se intenta crear un efecto de objetividad a través de una narración que anula o esconde la distancia entre el evento y su representación. Como lo explica Magdalena Perkowska citando a Benveniste:

The third person voice feigns to make the world speak itself, it masks the presence of a speaking subject and insinuates that the events tell themselves. This dissimulation seeks 
to produce the effect of a history being objective, neutral, transparent, and impersonal representation of reality, devoid of passions, preferences, subjective evaluations, and discursive distortions. (Perkowska 256)

Es esta pretensión de objetividad presente en las crónicas oficiales sobre el viaje lo que molesta a Juanillo, dice Juanillo en la novela “... aquel Pigurina o Pigafeta o cómo se llamase, y que se pasaba los días observándolo todo sin jamás ensuciarse en nada las manos, como no fuera con la tinta que tomaba sus notas...” (Baccino 77). Es por ello que Baccino elige al Bufón como narrador de la historia, con la intención de crear una nueva perspectiva, la posición de Juanillo como bufón de la flota le permite a Baccino adentrarse en la exploración de los aspectos psíquicos de los personajes: su estado de ánimo, sus fantasías, sus obsesiones, sus miedos, sus sueños, es decir en la dimensión subjetiva de la historia. Como sostiene Giraldi-dei-Cas, el narrador Juanillo desmitifica a los agentes históricos mostrando que ellos son también "instrumentos de sus propias obsesiones y pasiones” (Giraldi dei-Cas 268). En una entrevista con Juanamaría Cordones Cook Baccino se refiere a Juanillo como un "psicoanalista salvaje que está permanentemente ejerciendo un terrorismo intelectual y emocional. Pero para hacer esta gimnasia, peligrosa ciertamente...también tiene que bucear en su propia locura” (Cordones Cook 105). Lo mismo podríamos decir de Sancho Panza y su relación con Don Quijote. La introducción de la dicotomía locura-cordura así como también la primacía del diálogo y la intertextualidad nos permiten reconocer en la novela la gran herencia cervantina. Nuevamente refiriéndose a Juanillo sostiene Baccino "Es un individuo que no niega que la frontera entre locura y cordura es muy estrecha cuando existe, que caminamos con un pie en cada lado. Al contrario, él apela a esta línea divisoria, imaginaria” (Cordones Cook 105). La narración de Juanillo lejos de detenerse en la descripción de la flora, la fauna y el clima de las islas como lo hacen los cronistas, se detiene en el complejo laberinto de las relaciones humanas, intra e interpersonales que se forjan a lo largo del viaje.

En Maluco no hay pretensión de objetividad sino que se reconoce y se pone de manifiesto el carácter conflictivo de la relación entre experiencia y discurso:

Wherea's Pigaffeta's chronicle coated its surface with the non-problematic exchange between experience and referential discourse, Juanillo's narrative acknowledges his own narrative frame and place (lessness) of enunciation as he recounts his version of a voyage silenced by death, fear, and the opportunistic maneuvers of Pigaffeta's script. (Bishop 59)

La inclusión del yo autobiográfico en la novela introduce una dimensión subjetiva e interpretativa a la historia. No se pretende velar la posición de enunciación frente a los hechos ni se niega la artificialidad propia de toda narración. Por el contrario los lugares de enunciación y recepción así como el proceso mismo de escritura se abordan expresamente a lo largo de la novela, creando un fuerte componente de autorreferencialidad. Un ejemplo de autorreferencialidad lo encontramos en el capítulo VIII cuando Juanillo se detiene en la descripción de las formas vegetales y animales que habitan en la laguna e interrumpe su descripción para referirse a su interlocutor: 
No quiero abrumarte con un catálogo completo, cuanto más que ambos tenemos poco tiempo ya; pero debo mostrarte algunas pues así me lo imponen las reglas que rigen ésta y cualquier narración. ¿De qué otro modo podía darte la sensación del tiempo que transcurre mientras Enrique va y viene? (Baccino 234)

En este pasaje y en el siguiente se aborda explícitamente la cuestión de la temporalidad narrativa que dependerá del artificio del escritor-hombre que escribe dichas páginas:

Dejo la flota detenida en el mar del Sur el tiempo que quiera y abro un paréntesis. Paréntesis, Alteza. Para recordarte que quien escribe estas páginas no es Dios, ni la musa fulana o mengana, ni una quimera cualquiera; sino Juanillo Ponce, de carne y hueso como cualquier hijo de vecino. Por lo tanto si el discurso tiene continuidad y os da la sensación que lo he plumeado de una sentada y sin parar para comer una tortilla o dar una meada a las plantas del huerto, te equivocas. Que es mentira, puro artificio. Trucos que uno aprende para ocultar sus vergüenzas, disimular sus afanes, disfrazar sus miserias. (Baccino 206)

La continuidad del discurso se verá fragmentada en reiteradas ocasiones cuando la narración de Juanillo se acerque al sitio del trauma. Su posición de testigo participante de los acontecimientos históricos lo enfrenta por momentos a la imposibilidad de transmitir la experiencia vivida, a la insuficiencia del lenguaje que tanto han trabajado los poetas; ¿Cómo narrar la historia del sufrimiento humano vivido en el viaje sin digresiones, interrupciones, repeticiones en el discurso que den cuenta de lo incomprensible de dicha experiencia; sin una metáfora, sin un silencio que intenten nombrar lo innombrable?

EL TESTIMONIO DE UN TRAUMA HISTÓRICO

En su trabajo "Education and crisis” Shoshana Felman sugiere al testimonio como el modo privilegiado de comunicación en nuestros días, el género literario por excelencia en lo que llama "the era of testimony": "testimony have become a crucial mode of our relation to events of our times- our relations to the traumas of contemporary history: The second World War, the Holocaust, The Nuclear bomb, and other war atrocities” (Felman 16). La proliferación de estudios sobre el testimonio y sobre el trauma histórico nace de una misma preocupación contemporánea por enfrentar y recuperar un pasado que ha dejado fuertes huellas. En el caso de Juanillo el testimonio se entronca con una larga tradición de narración autobiográfica; la tradición picaresca.

En Maluco, Juanillo es testigo de un evento histórico potencialmente traumático, como testigo decide dar testimonio de los hechos a través de la narración de sus memorias. Juanillo escribe su testimonio del viaje de Magallanes muchos años después ya en su vejez. El lector no tiene acceso a "lo real”, a la experiencia del viaje como sitio del trauma histórico, sino a la reconstrucción mnemónica realizada por Juanillo. Es decir que lo real es inaccesible y a veces intransferible e incomunicable, solo accedemos a lo real a través de lo simbólico. La narración del trauma es una narración diferida "It is in and through writing that memory constructs itself as inevitabley belated” (Nicola 9). La narración de 
Juanillo puede ser entendida entonces como "a belated response to and later reworking of an original trauma” (Nicola 19).

Utilizo aquí la noción de trauma histórico en el sentido que le da LaCapra "Historical trauma is specific and not everyone is subject to it" (LaCapra 722). "Historical trauma is related to particular events that do indeed involve losses. Everyone is subject to structural trauma. But, with respect to historical trauma, and its representation, the distinction among victims, perpetrators and bystanders is crucial" (LaCapra 723). El trauma en la novela es la experiencia concreta del viaje: es la sangre que "tiñe de rojo el turquesa de la laguna”, es el miedo y el terror a lo desconocido, es la incertidumbre y pérdida de todo referente de identidad, es Juanillo vistiendo la armadura de un muerto, es la decapitación de sus compañeros, es la mudez de Andrés el cartógrafo, la imagen de lo ominoso que despierta su boca sin lengua, es la locura de Gonzalvo, son "las llagas del sol, tumores en la espalda, espasmos de las tripas vacías” (Baccino 169).

La narración de Juanillo intenta recuperar la experiencia vivida, en un intento de dar forma a esa acumulación de memorias fragmentadas, resignificarlas dentro de una narración que le de sentido a lo vivido. Su testimonio es parte del trabajo de elaboración necesario para recuperar, a través de nuevos procesos de simbolización, una identidad fragmentada. En este sentido la narración de Juanillo da cuenta del proceso psíquico al que se refiere Nicola "The work of the imaginary and the symbolic upon the real” (180). Como sostiene Giraldi-dei-Cas, el viaje que describe Juanillo en su testimonio es un viaje marcado por el horror, del cual sobreviven solamente dieciocho hombres que llegan a Sevilla al borde de la locura. Únicamente Juanillo logra reconocer las costas europeas al visualizar el peñón de Gibraltar: “Al atardecer se han acercado tanto que no tiene dudas: es el peñón de Gibraltar dibujándose a lo lejos como una madre que espera a sus hijos en la puerta de su casa” (Baccino 298). ¿Cómo logra Juanillo salvarse de la locura? ¿Es su mirada irónica como propone Giraldi lo que lo salva, o es su creatividad, su fantasía, su capacidad de simbolizar lo ocurrido, dar palabras al dolor que otros callan?

La temporalidad diferida del testimonio supone una relación particular del sujeto con la experiencia vivida, relación que Nicola describe del siguiente modo: "The paradoxical knowing and not knowing is the position of any autobiographical narrator, who, in the present moment of the narration, possesses the knowledge that she/he did not have "then" in the moment of the experience" (Nicola 2). Esta dialéctica entre saber y no saber, comprender y no comprender, es propia del trauma y atraviesa la narración de Juanillo.

En el capítulo VIII de la novela la narración de Juanillo se acerca a lo incomprensible del trauma histórico; allí se narra la batalla sangrienta en la que muere Magallanes. Juanillo hace énfasis en esta dialéctica entre comprensión e incomprensión, entre lo dicho y lo no dicho, propia del trauma, la muerte se rodea de misterio, priman las contradicciones en el discurso, la imposibilidad de enfrentar ciertos temas, la negación. El desconocimiento de los hechos es mayor por encontrarse Juanillo "marginado de los acontecimientos” ubicado en la parte de la nave dedicada a los enfermos "Silenciosos, Furtivos, Expectantes" (Baccino 227). Las contradicciones entre el discurso de negación propio de los tripulantes y la realidad de las imágenes percibida por Juanillo desde la nave atraviesan su narración: 
Y el capitán irritado quiere darles una lección. Así que salta a tierra con cuarenta hombres armados. Y quema cuarenta casas...y también las canoas. Y muchos de los habitantes...Y yo, cuando traen la comida: si es cierto lo que cuentan que ha pasado en la isla. Y ellos: que no. Si no ha pasado nada. Aunque a veces las llamas iluminan la playa por la noche. Y Serrano se lava las manos en el agua límpida de la laguna antes de subir a platicar con el capitán. Y las manos de Serrano tiñen de rojo el turquesa de la laguna. (Baccino 231)

La narración de Juanillo da continuidad y la ilusión de una temporalidad lineal a memorias confusas de acontecimientos nunca totalmente asimilados ni comprendidos. Pero dicha continuidad se ve interrumpida a lo largo de la narración cuando la memoria de Juanillo se acerca al sitio del trauma. La fragmentación discursiva, las digresiones, interrupciones y repeticiones aparecen a nivel discursivo como síntomas del trauma, de aquello que escapa toda simbolización: "Trauma involves the inability to process the reél into the narrative as symbolization” (Caruth, Trauma 173). En este capítulo la memoria traumática dominada por la repetición predomina sobre la memoria narrativa a través de la cual Juanillo es capaz de simbolizar y narrar lo ocurrido. Como sostienen van der Kolk y van der Hart "the crucial factor that determines the repetition of trauma is the presence of a mute, unsymbolized, and unintegrated experience” (van der Kolk 167). Juanillo repite las mismas palabras una y otra vez, el discurso se vuelve fragmentado, incoherente, confuso:

Y yo: ¿qué ha pasado allá? Aunque me de vergüenza enseñar mi boca así. Igual: ¿Qué ha pasado allá? Y ellos sin mirarme: que nada. Que no ha pasado nada. Y vuelven con otras cosas y no ha pasado nada. Y se hace la noche y no ha pasado nada. Y las llamas iluminan la playa y no ha pasado nada. Y nos damos a la vela porque el maluco está a un paso, y no ha pasado nada. (230)

Frente a la confusión e incomprensión Juanillo reproduce una y otra vez una imagen visual que ha quedado grabada en su mente y que contrasta con el "no pasó nada” del discurso oficial: "y la sangre tiñe de rojo las aguas de la laguna que son de un verde turquesa y la mancha crece y la vida se achica” (Baccino 231, 252, 254). Como sostiene Cathy Caruth; "the traumatized witness compulsively returns to the unassimilated image of the trauma because the experience was never fully experienced as it occurred" (164) "The traumatized witness returns to the unassimilated image repeatedly attempting an interpretation that can be integrated into the historical present” (Caruth 169). Con estos quiebres en el discurso Juanillo expresa por momentos su imposibilidad de traducir al lenguaje su experiencia:

Por eso, Alteza, es que muchas veces, como ahora, me da rabia la continuidad de mi discurso. Vergüenza me da pensar que la tranquilidad, que la protección que da esa continuidad, sea a costa de esconder mis llagas, de desaparecer tras la máscara de las palabras, tras los rostros de los personajes, tras las penas inventadas de esos seres fantasmales que se mueven por las páginas que tanto te deleitan y afligen. Por eso Alteza, a veces me dan unas ganas locas de interrumpir mi discurso como ahora y dejar que se vuelva tan accidentado como la vida misma. (Baccino 217) 
En el capítulo XIX Juanillo narra las distintas reacciones de los tripulantes frente a la muerte del Capitán y los principales oficiales: la locura de Carvajo, la negación general frente a la muerte, la necesidad de huir "No tanto para dejar atrás los peligros como para poner distancia entre nosotros y los terribles acontecimientos que allí habían tenido lugar” (Baccino 281). Juanillo hace alusión también a las repercusiones de dicha experiencia traumática en el discurso de los tripulantes;

La gente hablaba de los muertos como si estuvieran vivos. Conjugaban mal los verbos y luego se rectificaban con aire atónito, entonces se abría un espacio negro en la frase que se quedaba por la mitad. Se empeñaban en no nombrarlos y construían frases sin sujetos. Pero el predicado, por cauto que fuera y sobre todo el verbo, siempre en condicional, los delataba. (Baccino 281)

La desolación y desorientación crecen a medida que avanza el viaje "Y navegábamos a tientas, sin rumbo y sin control, como quien se pasea por su casa en medio de la noche para olvidar una terrible pesadilla" (Baccino 281). Los tripulantes se encuentran a bordo de una nave sin dirección, Andrés el cartógrafo ha muerto y el capitán también: “nadie daba órdenes ni tenía claro el paso siguiente ni el rumbo que había que seguir” (Baccino 281). Luego de la batalla, el ritmo narrativo propio del capítulo VIII se enlentece, al ruido y el estrépito de los arcabuces sigue un silencio de muerte. La inmovilidad se apodera de los tripulantes "estatuas en un parque abandonado" que son incapaces de tomar decisiones inmersos en el duelo por la pérdida de sus hombres:

Es que necesitábamos tiempo para habituarnos a sus súbitas ausencias y a considerarlas definitivas. Eso era lo más difícil. Habíamos compartido durante veinte meses el estrecho territorio de las naves. Y el más estrecho del hambre y el miedo. Y el aposento sin ventanas de la incertidumbre. Y el calabozo de la angustia. Y el pozo de la desesperación. (Baccino 281)

En su estudio sobre el testimonio y su relación con el trauma histórico Shoshana Felman se refiere a la fragmentación presente en todo testimonio: “As a relation to events testimony seems to be composed of bits and pieces of a memory that has been overwhelmed by occurrences that have not settled into understanding or remembrance...” (Caruth, Trauma). El testimonio nos habla sobre eventos históricos que no han sido totalmente asimilados ni comprendidos "events which cannot be fully known or registered by the subject, and which therefore set in motion complex processes of revision and retranslation" (Caruth, "Trauma, Silence, and Survival” 13). De ahí la particularidad y riqueza del testimonio como modo de conocimiento "What the testimony does not offer is...a completed statement, a totalizable account of events. In the testimony language is in process and in trial, it does not possess itself as a conclusion, as the constatation of a veredict or the self-transparency of knowledge” (Caruth, "Trauma, Silence, and Survival” 16-17).

A través de la incorporación de lo traumático en la historia de Juanillo Baccino señala la falacia e imposibilidad de que toda historia sea una totalidad coherente a la que 
accedemos a través de un discurso continuo y racional, sin digresiones ni quiebres. ¿Cómo preservar la memoria de lo contradictorio y ambiguo? ¿Cómo nombrar el sufrimiento humano? Como sostiene Cathy Caruth:

It is here in the equally widespread and bewildering encounter with trauma that we can begin to recognize the possibility of a history that is no longer straightforwardly referential. Through the notion of trauma we can understand that a rethinking of reference is aimed not at eliminating history but at resituating it in our understanding, that is, at precisely permiting history to arise where immediate understanding may not. (Caruth, Unclaimed Experience 11)

En el testimonio de Juanillo no encontramos ni la continuidad discursiva ni la transparencia presentes en la narración de Pigafetta, sino por el contrario se nos transmite la dificultad que siente Juanillo en la tarea de rememorar las experiencias vividas y representarlas por escrito. Ya mencionamos antes la distancia conflictiva que existe entre la experiencia y su representación discursiva, podemos agregar ahora que esta distancia se hace mayor cuando el contenido de la experiencia es traumático para el sujeto que intenta recordarla:

Sepa Don Carlos que fueron días de una tremenda confusión y que aún hoy, tantos años después, me cuesta ordenar los hechos, a aun saber cuales ocurrieron fuera de mí y cuáles son meras proyecciones de mi atribulado interior. Porque, como te digo, fueron días de una terrible confusión. (Baccino 280)

Juanillo al escribir su testimonio se enfrenta a la ardua tarea de recuperar los acontecimientos históricos vividos muchos años atrás y representarlos frente a su lector Carlos V: “¿Sabes Alteza que todavía lloro cuando recuerdo la escena que sigue?” (252). La memoria entendida como un proceso por medio del cual se negocia la relación entre el evento y su representación juega un papel central en la narración. Como sostiene Nicola:

In much conventional autobiography, these narratives tend to elide memory as a process: the content is presented as if it were uniformly and objectively available to the remembering subject, as if the narrating "I" and the subject of the narration were identical. (Nicola 3)

En el testimonio de Juanillo, a diferencia de lo que ocurre en las crónicas oficiales del viaje, se pone en evidencia la memoria como proceso: "No recuerdo exactamente el orden de los parlamentos ni tengo más ganas de inventártelos, como hice y haré otras veces que sea menester” (105) y más adelante:

no quiero revivir aquellos meses lánguidos, quiero decirme a mi mismo que en nada me afectaron, Que salí intacto de aquel encierro. Quiero convencerme, quiero olvidar el frío, el hambre, el miedo. Sobre todo el miedo. ¿Por qué será que es tan difícil olvidar el miedo? (Baccino 173) 
El olvido, nos dice el psicoanálisis, requiere un trabajo de duelo, un trabajo de elaboración en donde se reconozca la pérdida. Por el contrario aquello que se reprime, que no puede recordarse, vuelve a aparecer, se repite una y otra vez. Para olvidar Juanillo debe ser capaz de comprender lo ocurrido, nombrarlo, darle un sentido a través de su narración. Es a partir de este revivir de la experiencia que supone la narración como acción diferida que se abre el camino para el olvido. A través de su narración Juanillo intenta elaborar lo traumático de su experiencia, su testimonio se convierte en un espacio de construcción y reconstrucción de la memoria, en un espacio de negociación entre memoria y olvido en el cual se ponen en marcha procesos incesantes de traducción y resignificación de las memorias.

\section{BibliografíA}

Baccino, Napoleón. Maluco: La novela de los descubridores. Barcelona: Seix Barral, 1992.

Bishop Jara, Ahna. Metahistories: Constructions of memory in Contemporary Latin American Fiction. Minneapolis: University of Minnesota, 2001. 147-179.

Caruth, Cathy. Unclaimed Experience. Trauma, Narrative and History. Baltimore: The Johns Hopkings University Press, 1996.

Trauma: Explorations in Memory. Baltimore: The Johns Hopkins University Press, 1995.

“Trauma, Silence and Survival”. Between the Psyche and the Polis: Refiguring History in Literature and Theory. Michael Rossington y Anne Whitehead, eds. Aldershot, Burlington, VT: Ashgate, 2000.

Cordones-Cook. "Contexto y proceso creador en Maluco. La novela de los conquistadores”. Chasqui: Revista de Literatura Latinoamericana 22/2 (1993 nov): 103-108.

De Luján Campos, María Luisa. “Maluco y la pendularidad de sus opuestos”. Historia, ficción y metaficción en la novela latinoamericana contemporánea. Buenos Aires: Ediciones Corregidor, 1996. 70-89.

Felman, Shoshana "Education and Crisis". Trauma: Explorations in memory. Cathy Caruth, ed. Baltimore: The Johns Hopkins University Press, 1995. 13-60.

Fiddian, Robin. "Séance Fiction: Confronting the ghost(s) of the Mexican Revolution in 'Madero, el otro' by Ignacio Solares”. Between the Psyche and the Polis: Refiguring History in Literature and Theory. Michael Rossington y Anne Whitehead, eds. Aldershot, Burlington, VT: Ashgate, 2000.

Filer, Malva. "La Historia apócrifa en las novelas de los posmodernistas rioplatenses". Alba de América: Revista Literaria 12/22-23 (1994): 193-201.

“Maluco: re-escritura de la Expedición de Magallanes”. Actas Irving 92: Encuentros y Desencuentros de Culturas: siglos XIX y XX. Vol 4 Juan Villegas, ed. Irvine: University of California, 1994. 293-301.

Freud, Sigmund. "Remembering, Repeating and Working Through”. The Freud Reader. Peter Gay, ed. New York: Norton, 1995. 
"Recordar, repetir y reelaborar: nuevos consejos sobre la técnica del psicoanálisis, II”. Obras completas XII. Buenos Aires: Amorrortu Editores, 1990. 145-57.

Garramuño, Florencia. Genealogías culturales: la reescritura en la novela contemporánea. Diss. Princeton University, 1995. Ann Arbor: UMI, 1996.

Giraldi-dei-Cas, Norah. "Maluco la novela de los descubridores”. Historia, Espacio e Imaginario. Villenueve d’Ascq (Nord): Presses Universitaires du Septentrión, 1997.

Hernández, Mark. "The bufón and the Voyage of Magellan in Napoleón Baccino Ponce de León’s Maluco: La novela de los descubridores”. Chasqui: Revista de Literatura Latinoamericana 30/1 (mayo 2001): 3-13.

Iniesta Cámara, Amalia. "El nuevo Mundo en la crónica y la fábula”. Anclajes: Revista del Instituto de Análisis Semiótico del Discurso II/2 (1998): 57-76.

LaCapra, Dominick. “Trauma, Absence and Loss”. Critical Inquiry 25 (Summer, 1999): 696-727

Laplanche, Jean y J. B Pontalis. The Language of Psychoanalysis. New York: Norton, 1974.

López, Kimberle. Latin American Novels of the Conquest : Reinventing the New World. Columbia: University of Missouri Press, 2002.

Mignolo, Walter. “Cartas, crónicas y relaciones del descubrimiento y la conquista”. Historia de la literatura hispanoamericana. Tomo I. Luis Iñigo Madrigal, ed. Madrid: Cátedra, 1982. 57-116.

Moreno Turner, Fernando. "Parodia, metahistoria y metaliteratura (en torno a Maluco de Napoleón Baccino Ponce de León)”. Hispamérica: Revista de Literatura XXVIII/82 (1999): 3-20.

Nicola, King. Memory, Narrative and Identity. Edinburgh: Edinburgh University Press, 2000.

Perkowska-Alvarez, Magdalena. “A Fool’s Point of View: Parody, Laughter, and the History of the Discovery in 'Maluco; la novela de los descubridores' by Napoleón Baccino Ponce de León”. A Twice-Told Tale: Reinventing the Encounter in Iberian/ Iberian American Literature and Film. Juan Navarro y Theodore Robert Young, eds. Delaware: University of Delaware Press, 2001. 253-274.

Pigafetta, Antonio. Primer viaje en torno del globo. Madrid: Espasa-Calpe, 1963.

Schweizer, Harlod. Suffering and the Remedy of Art. Albany: State University of New York Press, 1997.

Van der Kolk, Bessel y Onno Van der Hart. “The Intrusive Past: The Flexibility of Memory and the Engraving of Trauma”. Trauma: Explorations in Memory. Cathy Caruth, ed. Baltimore: The John Hopkings University Press, 1995. 158-182.

Vich, Cynthia. "El diálogo intertextual en Maluco”. Revista Iberoamericana LXIII (1997): 405-418. 